\title{
Experimentation Abilities in Kindergarten Children with Learning Problems
}

\author{
Joep van der Graaf 1,2*, Eliane Segers 2, 1, Ludo Verhoeven ${ }^{2}$ \\ ${ }^{1}$ University of Twente, De Zul 10, 7500 AE Enschede, NETHERLANDS \\ ${ }_{2}^{2}$ Radboud University, Comeniuslaan 4, 6525 HP Nijmegen, NETHERLANDS
}

*Corresponding Author: j.vandergraaf@utwente.nl

Citation: van der Graaf, J., Segers, E. and Verhoeven, L. (2018). Experimentation Abilities in Kindergarten Children with Learning Problems. European Journal of STEM Education, 3(3), 13. https://doi.org/10.20897/ejsteme/3873

Published: September 6, 2018

\begin{abstract}
In the present study we investigated experimentation abilities of children with learning problems in early childhood education, i.e. kindergarten (4-6 years old). An essential part of science education is learning via the scientific method, of which experimentation is the central component. We studied experimentation abilities in 28 kindergartners with mild learning problems and compared them to 45 grade-matched typically developing kindergartners. Moreover, it was examined to what extent linguistic and cognitive factors in experimentation could be identified. The results showed that the kindergartners with learning problems scored lower on experimentation, which was due to the difficulty they experienced when the number of variables increased. There was an overlap in performance of kindergartners with and without learning problems, which showed that some kindergartners with learning problems performed similar to typically developing kindergartners on the experimentation task. Similar cognitive and linguistic factors in experimentation were found as in their typically developing peers, namely nonverbal reasoning and grammar. The results suggest that kindergartners with learning problems show a developmental delay in experimentation. Instructional methods for children with learning problems should take these individual differences and developmental delay into account. An important conclusion is that kindergartners with learning problems can design multivariable experiments.
\end{abstract}

Keywords: scientific reasoning, experimentation, learning problems, kindergarten, individual differences

\section{EXPERIMENTATION ABILITIES IN KINDERGARTEN CHILDREN WITH LEARNING PROBLEMS}

To be prepared for the modern, technology-rich society, it is expected that students learn to think independently and critically (Fischer et al., 2014). This mindset has given rise to an increase in the number of students in subjects, such as science, technology, engineering, and math (STEM; Freeman et al., 2017). This so-called STEM education revolves around scientific reasoning abilities. Scientific reasoning consists of generating hypotheses, designing experiments to test them, and evaluating evidence to draw conclusions (Klahr, 2000). Independent learning can take place when these abilities are mastered (Andersen and Garcia-Mila, 2017). In addition, it can help students think critically about presented results or their origin. Therefore, science education should be accessible from early childhood for everyone, including children with learning problems. It is important that the consequences of learning problems are recognized and that appropriate education is provided. This means that the difficulties of children with learning problems should be identified, their education should address specific strategies and skills and their transfer to other domains, address linguistic and cognitive limitations, and use implementation features 
that optimize instructions (Fuchs and Fuchs, 2015). It is therefore relevant to identify the capabilities of children with learning problems in science education. A key aspect in providing effective science instruction to young children is that it should be based on the child's needs and talents, and even more so for children with learning problems (Alber-Morgan et al., 2015). Children seem to learn more from instruction that is contextualized (Boaler, 1993). For experimentation, the instruction can be contextualized by providing hands-on activities (Bay et al., 1992). In a similar hands-on context, it has been shown that kindergartners without learning problems can correctly design experiments with multiple variables (Van der Graaf et al., 2015). The present study investigated the experimentation abilities of kindergartners (age four to six years old) with learning problems with the aim to assess their difficulties in the specific ability of experimentation (in comparison with kindergartners in mainstream education), to assess the individual differences in order to identify linguistic and cognitive limitations, and to provide suggestions to optimize instruction.

\section{Experimentation}

Experimentation abilities consist of designing and conducting experiments. The experiments should be designed in such a way that one can learn from the outcome of the experiment. Experimentation is one of the core abilities of scientific reasoning (Klahr, 2000). Inhelder and Piaget (1954) were sceptical on whether kindergartners could design multivariable experiments correctly, as they refer to themselves as causing the effect. In a similar vein, the ability to incorporate a second variable in their predictions and explanations was expected to be too difficult (Siegler and Chen, 1998), as would be the ability to adjust their own beliefs (Wilkening and Huber, 2004). However, in a dynamic assessment, when kindergartners receive feedback based on their performance, it has recently been shown that they can learn how to design multivariable experiments correctly (Van der Graaf et al., 2015). This indicates that kindergartners can understand the control of variables strategy (CVS). The CVS states that to find out what the effect of a single variable is, one has to manipulate that variable, while controlling all other variables (Chen and Klahr, 1999).

\section{Individual Differences}

Individual variation in scientific reasoning in primary school children can be explained to a large extent by cognitive and linguistic abilities. First, experimentation abilities in kindergarten have been shown to be related to inhibition, verbal working memory, and grammar (Van der Graaf et al., 2016). Inhibition can aid in the rejection of intuitively derived misconceptions (Kuhn and Franklin, 2006), which helps to focus on the task at hand, namely to find out the effect of a variable. This way, inhibition allows children to learn to design experiments using the correct strategy (i.e., CVS). Second, verbal working memory and grammar were found to be related to experimentation (Van der Graaf et al., 2016). Verbal working memory was suggested to be a prerequisite to monitor the use of the CVS and applying its rules to determine the settings of the variables. In the case of children with learning problems, verbal working memory might be a critical factor in scientific reasoning, given the limited capacity of the working memory of children with learning disabilities (Siegel and Ryan, 1989). A third feature of science education is that it requires understanding of complex grammatical structures that are needed to ask questions, explain, predict, and reason (Dawes, 2004). Fourth, vocabulary has been linked to performance on an experimentation task. The gains on a transfer task, in which CVS also had to be applied, were found to be partly explained by vocabulary (Wagensveld et al., 2015). Finally, measures of reasoning (verbal and deductive) have been found to explain performance in experimentation and scientific reasoning in general. In 12-year-olds (Siler et al., 2010), and 10- and 12-year-olds (Wagensveld et al., 2015) verbal reasoning was found to explain learning to understand and apply the CVS. In another study, a paper-and-pencil test was used to assess 10-year-olds' scientific reasoning, including how to design experiments (Mayer et al., 2014). In that study scores on this questionnaire were related to performance on a problem-solving task in which planning and deductive reasoning are involved. Whether linguistic and cognitive limitations apply to kindergartners with learning problems during experimentation the same way as for kindergartners in general or differently is yet unknown. The individual differences in experimentation of kindergartners with learning problems can provide useful guidelines for implementation of optimized instruction, so all children can practice relevant skills, such as independent and critical thinking, during scientific activities in the classroom.

\section{Children with Learning Problems}

Within the field of science education, Alber-Morgan et al. (2015), argued that children with learning problems should profit from the educational pursuit of excellence, just as their typically developing peers. This can be a challenge as adolescents with learning problems score lower on standardized science achievement tests than regular developing adolescents (Anderman, 1998). With respect to experimentation abilities in children with learning problems, hands-on experimentation has been shown to stimulate learning (Bay et al., 1992). After five sessions of guided hands-on experimentation, a group of nine- to 12 -year-olds with learning problems remembered more 
about the material and applied their experimentation skills more easily to other situations, compared to five sessions of direct instruction. In other words, it seems to be conceivable for children with learning problems to use scientific discovery learning in order to learn domain-specific knowledge and domain-general experimentation abilities.

In a study by Van der Steen et al. (2012) the understanding of scientific concepts in three- to five-year-olds was investigated with a task that consisted of two different topics, namely air pressure and running balls. The experimenter demonstrated to the kindergartners how the materials worked. An assessment with scaffolding was used, which included follow-up questions depending on the child's level of understanding. The results revealed that the kindergartners with learning problems showed comparable understanding overall to the typically developing kindergartners. However, the kindergartners with learning problems gave more incorrect answers in general and they gave fewer answers that indicated a higher level of understanding. As in this study the experimenter demonstrated the materials to the kindergartners and coded their verbal understanding, it remains to be investigated to what extent kindergartners with learning problems can design hands-on multivariable experiments. It might be the dynamic assessment that is suitable for kindergartners with learning problems. The instructional design should manage the cognitive loads of the students with learning problems when performing inquiry learning activities (Lee and So, 2015). This can be done by step-by-step instruction to introduce multiple concepts, by showing worked examples, and by keeping a clear focus on the learning objective (Lee and So, 2015). The assessment of experimentation abilities can also be dynamic, such as using a step-by-step instruction by introducing the variables one by one (Van der Graaf et al., 2015). In addition, they used feedback with worked examples in which the experimenter explained whether an experiment was correct and why. When the design of the experiment was incorrect, the experimenter also explained and showed how it should have been set up. Finally, the kindergartners were provided with clear research questions, which they were asked to answer by designing an experiment. To what extent kindergartners with learning problems have difficulties in using the CVS during experimentation remains to be investigated, as well as whether they experience the same difficulties as kindergartners in mainstream education.

\section{The Present Study}

In summary, kindergartners can design multivariable experiments when dynamic feedback is given (Van der Graaf et al., 2015). This instructional approach might have benefits for kindergartners with learning problems (Lee and So, 2015). When it is known whether this instructional method proves fruitful for kindergartners with learning problems, it can be used in science education of children with learning problems. Various cognitive and linguistic factors have been related to scientific reasoning of children in primary school. It remains to be investigated which cognitive and linguistic factors can explain their performance on an experimentation task. Therefore, the present study investigated experimentation abilities in early childhood of kindergartners with learning problems compared to typically developing kindergartners. Moreover, individual differences in experimentation of kindergartners with learning problems were also investigated, as these might provide guidelines for teaching of experimentation abilities. It was expected that kindergartners with learning problems would score lower on the experimentation task than kindergartners in mainstream education. Furthermore, it was explored to what extent cognitive measures (nonverbal reasoning and inhibition) and linguistic measures (vocabulary, grammar, and verbal working memory) would predict the performance of kindergartners with learning problems on the experimentation task.

\section{METHOD}

\section{Participants}

A total of 73 kindergartners participated in this study. The study included 28 kindergartners with learning problems from one elementary school for special education, and 45 kindergartners from an elementary school for mainstream education. The average age of the participants with learning problems was 6 years and 4 months (SD $=11$ months). Among them were 13 girls and 15 boys. Children without learning problems were in the first year of kindergarten, 14 girls and 8 boys, or the second year of kindergarten, 9 girls and 14 boys. These kindergartners were aged 5 years and 4 months on average ( $S D=8$ months), and had already participated in a preceding study of the authors in 2015. Comparing the two groups, the kindergartners with learning problems were older, $t(70)=$ $5.53, p<.001$, Cohen's $d=1.34$, and scored lower on the standard score of non-verbal reasoning, $t(70)=5.19, p$ $<.001$, Cohen's $d=1.25$, than kindergartners without learning problems.

All children were in the first or second year of kindergarten. This is a program of two years in the Netherlands before formal education starts. The special education school did not differentiate between these two kindergarten years. In the Netherlands, there are three types of primary education: mainstream education, special education for children with mild learning problems, and special education for children with severe learning problems (Ministerie van Onderwijs, Cultuur, en Wetenschap [Ministry of Education, Culture, and Science], 2014). In this study, 

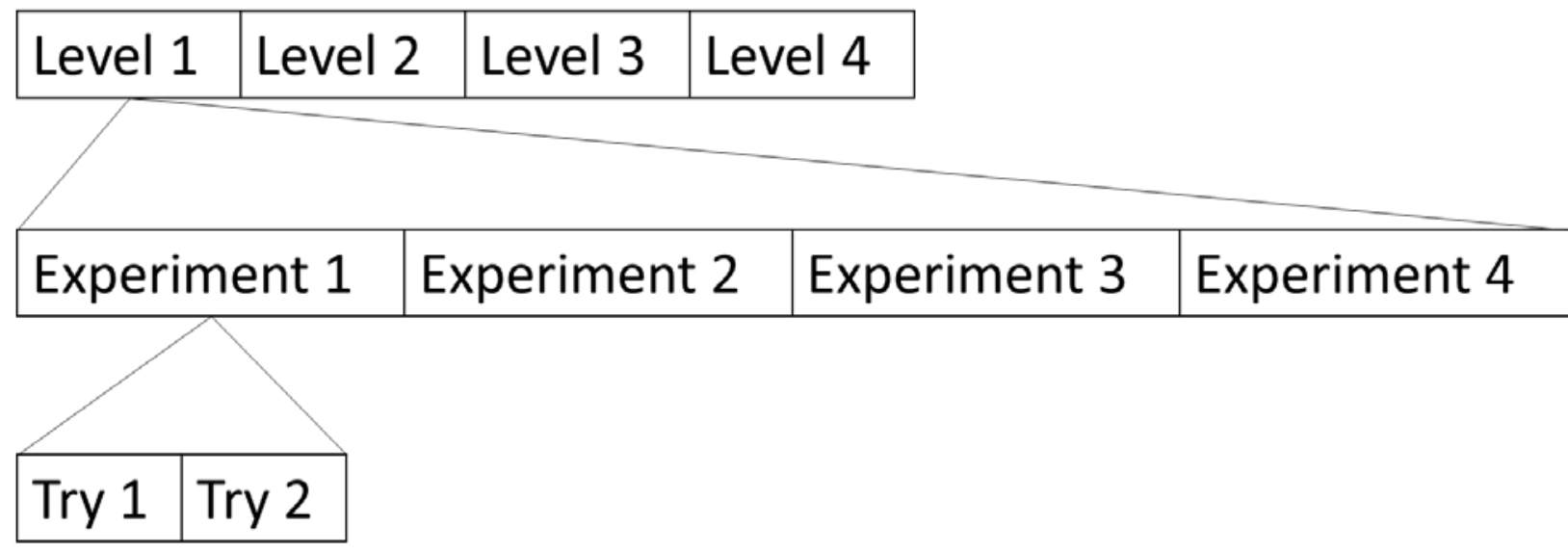

Figure 1. A schematic overview of the levels and experiments in the experimentation task

kindergartners from special education schools for children with mild learning problems participated. These schools have the same end terms as mainstream schools. This means that the children with mild learning problems can continue their education at a regular high school. However, the children tend to have an extended trajectory of finishing school. An independent committee judges whether a child can enter special education for children with mild learning problems. The committee consists of at least one child psychologist (Ministerie van Onderwijs, Cultuur, en Wetenschap [Ministry of Education, Culture, and Science], 2016).

\section{Materials}

\section{Experimentation}

To measure experimentation abilities, two wooden ramps were used (cf. Chen and Klahr, 1999). The kindergartners were asked to design experiments with the two ramps. Each ramp had four different variables, namely the weight of the ball (light/heavy), starting position on the slope (high/low), steepness of the slope (steep/flat), and the surface of the slope (rough/smooth). To investigate a single variable, the kindergartners had to use the CVS to design experiments with multiple variables correctly. The kindergartners were asked to set up an experiment in order to answer a research question. The research question was given by the experimenter and was about studying the effect of one of the variables. To design an experiment, the kindergartners set up both ramps. Using two ramps has the advantage that the result can directly be seen, because one ball might roll further as the effect of manipulating a variable.

We used the same task procedure as Van der Graaf et al. (2015). This included a gradual build-up of the number of variables, and dynamic feedback was used. There were four levels of difficulty, see Figure 1. At Level 1, the kindergartners were allowed to set only one variable, at Level 2 two, at Level 3 three, and at Level 4 all four variables. Whenever at least one of the four experiments at one level was designed correctly, the kindergartner proceeded to the next level, and if not, testing was discontinued. The four experiments at one level each investigated a different variable. There were 16 experiments in total and each variable could be investigated four times (once at each level).

Regarding the dynamic feedback, the kindergartners were given a second try when their first design of the experiment was incorrect. When the second try was also incorrect, the experimenter explained that it was incorrect and why. The experimenter also showed how the experiment should have been designed by setting the two ramps correctly. Whenever a try was correct, the experimenter explained that the try was correct and why. This means that after every trial feedback was given.

Two scores were obtained: an experiment correct and a variable correct score. The experiment correct score was the sum of the correctly designed experiments, with a maximum score of 16 . The variable correct score was the sum of the correctly set variables. A point was given when the variable of interest was manipulated (i.e. set up differently between the ramps). Additional points could be scored from Level 2 onwards for each variable that was not under investigation. A point was scored when such a variable was controlled (i.e. set up similarly between the ramps). The maximum variable correct score was 40 . The experimentation task is valid and reliable (Van der Graaf et al., 2015).

\section{Nonverbal Reasoning}

Two versions of the same task to measure nonverbal reasoning were used in the present study. Since the sample of the kindergartners in mainstream education was tested earlier, they performed an older version of the test (Bleichrodt et al., 1987), while the kindergartners with learning problems performed a newer version of the test 
(Resing et al., 2012). The difference between the two versions was that some items were replaced with newer ones. Therefore, we used the standardized scores to compare the kindergartners from the different types of education, and we used the raw scores to analyse the individual differences in experimentation of the kindergartners with learning problems.

The task used was the exclusion task. An item consisted of four abstract figures of which three figures belonged to a single category and one of them was not a member of that category. The category included figures that shared a property, such as the size and number of the dots in the figures. The non-member then had a larger dot or an extra dot. The kindergartners were instructed to identify the non-member by pointing it out. Inductive reasoning was needed to identify the category and deductive reasoning has to be used to find the non-member. The task consisted of 30 items. In the old version, testing was discontinued if four consecutive items were answered incorrectly. In the new version, testing discontinued when four out of five consecutive items were responded to incorrectly. The raw score was the sum of correct responses. Reliability of both versions is good (Bleichrodt, et al., 1987; Resing, et al., 2012). The standard score was the raw score adjusted for age based on a large sample of children to create the standard scores (Bleichrodt et al., 1987; Resing et al., 2012). Standard scores have a mean of 15 and a standard deviation of 5 (Bleichrodt et al., 1987; Resing et al., 2012).

\section{Inhibition}

Inhibition was measured using the Head-Toes-Knees-Shoulders-task (Ponitz et al., 2009). The task consisted of two blocks. In the first block the kindergartners were asked to touch their head or toes, but the child's task was to do the opposite. In the second block the task remained the same, but the shoulders and knees were added. Each block consisted of 10 items. Two points were given for a correct response and one point was given when the child corrected itself. No points were given when the response was incorrect (i.e. when the child did respond as asked and thus did not produce an opposite response). The maximum score was 40 points. The task has been shown to reveal significant variability and construct validity with parent and teacher ratings (Ponitz et al., 2009; Wanless et al., 2011).

\section{Vocabulary}

Vocabulary was measured using the verbal meaning test (Resing et al., 2012). The child had to choose one out of four figures by pointing it out. The correct figure resembled the word, which was read aloud by the experimenter. If four out of five consecutive items were answered incorrectly, testing was discontinued. The task consisted of 40 items. The score was the sum of correct responses, with a total of 40 . Reliability of the verbal meaning test is excellent (Resing et al., 2012).

\section{Grammar}

A sentence-repetition-task was used to measure grammatical abilities (Verhoeven et al., 2013). The child had to repeat the sentence, which was read aloud by the experimenter. An example of a sentence was: "My friend wanted to bike to the city yesterday". The sentences increased in length. There were 12 sentences. When the sentence was repeated correctly, two points were scored. When one error was made, one point was given. When two or more errors were made, no points were given. The maximum score was 24. Reliability of this task is excellent (Verhoeven et al., 2013).

\section{Verbal Working Memory}

A word-repetition-task was used to measure verbal working memory (Verhoeven et al., 2013). The experimenter read a sequence of words out loud and the child's task was to repeat the words in the correct sequence. The task started with two sequences of two words. Every two sequences, the length of the sequence increased with one word. There were 12 sequences in total. The final two sequences consisted of seven words. When four successive sequences were repeated incorrectly, testing was discontinued. For each correctly repeated sequence one point was scored. The maximum score was 12 correctly repeated sequences. Reliability of this task is excellent (Verhoeven et al., 2013).

\section{Procedure}

The kindergartners in mainstream education only performed the experimentation task and the nonverbal reasoning task, while the kindergartners with learning problems performed all mentioned tasks. The kindergartners were tested individually, at their school in a quiet place. The tests were administered in two sessions of about 40 and 10 minutes (mainstream education) or in three sessions of 20 to 40 minutes (kindergartners with learning problems). Sometimes there was an extra break in the sessions of the kindergartners with learning problems, due to deviant behaviour. Each kindergartner was tested by a single experimenter. There was one experimenter for each school. Parents and/or caretakers were approached via the schools. They were informed about the research and gave consent for their children to participate in the present study. 


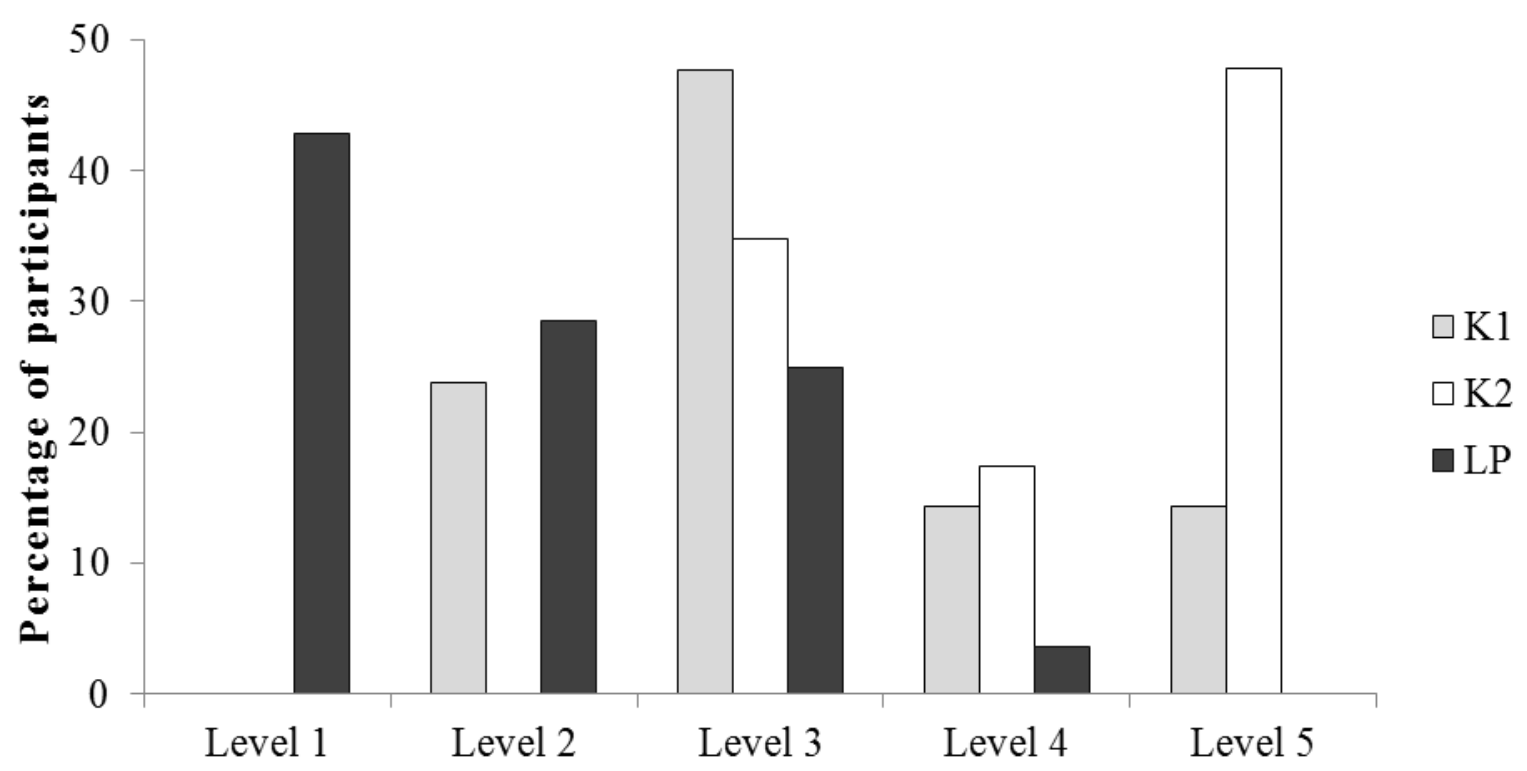

Figure 2. The percentage of participants per group (K1, K2, and LP) and the Level at which testing was discontinued. $\mathrm{K} 1=$ mainstream kindergarten year $1, \mathrm{~K} 2=$ mainstream kindergarten year 2, $\mathrm{LP}=$ kindergartners with learning problems

Table 1. Descriptive Statistics and Contrasts Between Kindergartners with Learning Problems and Kindergartners in Mainstream Education

\begin{tabular}{lcccccc}
\hline & \multicolumn{2}{c}{ Learning Problems } & \multicolumn{2}{c}{ Mainstream education } \\
\hline & $\boldsymbol{M}$ & $\boldsymbol{S D}$ & $\boldsymbol{M}$ & $\boldsymbol{S D}$ & $\boldsymbol{P}$ & Cohen's $\boldsymbol{d}$ \\
\hline Variable correct score & 6.11 & 7.09 & 28.71 & 11.49 & $<.001$ & 2.25 \\
\hline Experiment correct score & 2.14 & 2.41 & 6.82 & 3.17 & $<.001$ & 1.61 \\
\hline Nonverbal reasoning $^{1}$ & 7.32 & 5.57 & 13.61 & 4.64 & $<.001$ & 1.25 \\
\hline
\end{tabular}

Note. ${ }^{1}$ Standard scores were used for this comparison.

\section{RESULTS}

First, the performance on the experimentation task was analysed. Most kindergartners with learning problems could not design multivariable experiments correctly, while most kindergartners in mainstream education could, see Figure 2. In Figure 2, the number of participants is represented for which testing was discontinued at that level, because no experiments at that level were designed correctly. Level 5 was added as a category for kindergartners that could design experiments correctly at Level 4, so the participants at Level 4 did not design an experiment correctly at Level 4 . Some kindergartners with learning problems did design multivariable experiments correctly and about $30 \%$ of the kindergartners with learning problems reached Level 3 and Level 4 . To compare the kindergartners with and without learning problems, independent samples t-tests were conducted. The difference in performance with kindergartners from mainstream education was significant, $t(71)=10.39, p<.001$, Cohen's $d=2.25$ (equal variances were not assumed, Levene's $F=16.56, p<.001$ ) for the variable correct score, and $t(71)=6.69, p<.001$, Cohen's $d=1.61$ for the experiment correct score, see Table 1 . These differences can be considered large, since Cohen's $d$ is larger than 0.80 (Cohen, 1988).

Second, individual differences in experimentation were investigated. Experimentation correlated significantly with two cognitive factors, namely nonverbal reasoning and grammar, see Table 2 . The correlations with inhibition and vocabulary were approaching significance, $r(27)=.37, p=.056$ and $r(27)=.35, p=.072$, respectively. Verbal working memory was the only factor that did not show (a trend towards) significance of the correlation with experimentation. The factors were further investigated using multiple regressions. The factors were expected to be positively related to experimentation. As this was a directional hypothesis, one-tailed tests were used to evaluate the independent variables in the regression (Field et al., 2012). To do so, the p-values of the two-tailed tests of the independent variables, provided by SPSS (version 19), were divided by two. The backward-method was used to evaluate the regression models. The first model included all factors. Then, non-significant factors were removed from the model. This resulted in a regression model, adjusted $R^{2}=.31, F(2,24)=6.94, p=.004$, with two factors that related to experimentation, namely nonverbal reasoning, $\beta=.41, t(23)=2.32, p=.015$, and grammar, $\beta=.33$, $t(23)=1.87, p=.037$. 
Table 2. Descriptive Statistics and Pearson's r Correlations of all Measures for Kindergartners with Learning Problems

\begin{tabular}{|c|c|c|c|c|c|c|c|c|}
\hline & $M$ & $S D$ & 1 & 2 & 3 & 4 & 5 & 6 \\
\hline 1 Experimentation $^{1}$ & 6.11 & 7.09 & 1 & & & & & \\
\hline 2 Nonverbal reasoning & 17.61 & 8.50 & $.54 * *$ & 1 & & & & \\
\hline 3 Inhibition & 12.61 & 13.38 & $.37 \dagger$ & $.47^{*}$ & 1 & & & \\
\hline 4 Vocabulary & 22.43 & 7.09 & $.35 \dagger$ & $.44^{*}$ & .23 & 1 & & \\
\hline 5 Grammar & 3.93 & 2.70 & $.47 *$ & $.36 \dagger$ & .22 & $.35 \dagger$ & 1 & \\
\hline 6 Verbal working memory & 3.04 & 1.09 & .27 & $.51 * *$ & .14 & .17 & $.55 * *$ & 1 \\
\hline
\end{tabular}

Note. ${ }^{1}$ Experimentation was measured with the variable correct score. ${ }^{* *} p<.01,{ }^{*} p<.05,{ }^{\dagger} p<.10$.

\section{DISCUSSION}

The aim of the present study was to investigate experimentation abilities in kindergarten children with learning problems in order to identify their difficulties in experimentation and address their linguistic and cognitive limitation. The results showed that they score lower on the experimentation task than kindergartners without special educational needs. Nonverbal reasoning and grammatical abilities positively related to experimentation abilities of the kindergartners with learning problems.

About $30 \%$ of the kindergartners with learning problems designed multivariable experiments correctly. On top of that, more than half of the kindergartners with learning problems were capable of performing an experiment in which the effect of a single variable had to be found out. The results revealed that kindergartners in mainstream education score better than kindergartners with learning problems. However, there is overlap in the range of performance of kindergartners with and without learning problems. This is in line with the finding that kindergartners with learning problems perform comparable to typically developing kindergartners, but fewer reach a higher level of understanding (Van der Steen et al., 2012). This indicates that as a group, the kindergartners with learning problems show a slight delay in development compared to typically developing kindergartners.

The linguistic and cognitive factors that could explain variation in experimentation abilities were investigated. Nonverbal reasoning and grammatical ability explained the most individual variation in experimentation. Experimentation as part of scientific reasoning, involves various reasoning processes, such as inductive, abductive, and deductive reasoning (Dunbar and Klahr, 2012). Indeed, results from the present study indicated that nonverbal reasoning was related to experimentation. With respect to learning problems, nonverbal reasoning can be assessed in a screening procedure as it strongly relates to cognitive abilities, such as scientific reasoning in the present study. Another study has found that nonverbal reasoning is a predictor of later reading disabilities, even when other linguistic factors are controlled for, such as phonological processing (Fuchs et al., 2012). This way, early childhood education can be adjusted to the needs and talents of the students (Alber-Morgan et al., 2015).

Based on previous studies, it was expected that linguistic abilities related to experimentation (Van der Graaf et al., 2016). The present results revealed that grammatical ability related to experimentation. They share two properties; recursion and transition. Experimentation involves the recursive application of the correct design strategy to the different variables, and the strategy has to be transformed into a design. Grammar allows us to recursively built sentences and make them endlessly long, and it allows us to transition between phonology and semantics (Jackendoff, 2002).

In line with studies in mainstream education (Van der Graaf et al., 2016; Wagensveld et al., 2015), the present results showed correlations of nonverbal reasoning, grammar, and vocabulary with experimentation. One difference is that the present results revealed a near significant correlation of vocabulary with experimentation, while in typically developing children, a significant effect of vocabulary was found on gains in CVS usage (Wagensveld et al., 2015), but no effect of vocabulary on experimentation was found in kindergarten (Van der Graaf et al., 2016). The present results should be interpreted with caution given the near significance of the correlations and the small sample size. It might be that kindergartners with learning problems did not yet know all the words that were used in the instruction. Although the instruction was designed to be understandable for kindergartners and there was feedback on their performance, the instruction may still have included unfamiliar words. Prior vocabulary knowledge is important for learning new words, such as variable names, as young children rely on existing vocabulary knowledge during the acquisition of new vocabulary (Werker et al., 2002).

Inhibition also showed a near significant correlation with experimentation. In mainstream education inhibition significantly related to experimentation (Van der Graaf et al., 2016). This indicates kindergartners may use their inhibition to reject intuitively derived misconceptions (Kuhn and Franklin, 2006), such as that the ball would roll further when the surface is rough instead of smooth. Hence, making it easier to address the question posed, because their tendency to generate a desirable effect would be less. However, other factors, namely nonverbal reasoning 
and grammar, appeared to be more relevant in the present study. The role of inhibition should therefore be a topic for further investigation.

Verbal working memory did not relate significantly to experimentation. As was expected, the scores were low on this task. Kindergartners with learning problems could only repeat a sequence of three words correctly. Due to this floor effect, there was less variation that could explain performance on the experimentation task. Therefore, no conclusion can be drawn on the role of verbal working memory in experimentation in kindergartners with learning problems.

Given the large similarity of cognitive factors involved in experimentation for kindergartners with and without learning problems (cf. Van der Graaf et al., 2016), it appears that kindergartners with learning problems participate in scientific discourse in a similar vein as kindergartners in mainstream education, but their development is simply delayed. This means that the kindergartners with learning problems should be taught experimentation strategies in a similar vein as kindergartners without learning problems, but the level should be adjusted for developmental age. A number of suggestions for instruction of experimentation strategies follow from the present results that also apply to kindergartners with learning problems. The difficulty kindergartners experience when the number of variables increase should be taken into account. It might be possible to train inhibition and/or provide external control of their behaviour in order to improve experimentation abilities. The relevant language to talk about science should be taught (cf. Snow, 2010), and/or use the opportunity to explain the new concepts that emerge from the process of designing experiments. Adjusting the language use to the level of the learner can be exemplified by the gradual introduction of variables along with their names in the present study. It might be difficult for the children with learning problems to take the variables into account when they cannot name them. Pointing to objects could be a way to start using variables, but language seems to be needed for complex forms of thought (Luria and Yudovich, 1966). This also seems to be the case for science learning as children with learning problems have limited language abilities that can affect the efficiency of science learning (Parmar et al., 1994) and a similar reliance on language can be found in typically developing kindergartners when designing experiments (Van der Graaf et al., 2016). Therefore, language use should be taken into account when teaching science, but whether kindergartners with learning problems might profit more from such language-infused instruction of experimentation than kindergartners in mainstream education remains to be investigated. It would also be interesting to study to what extent non-verbal communication aids experimentation of kindergartners with learning problems and to what extent this type of communication might stimulate language use when talking about science.

Various interventions have been created that can improve scientific reasoning abilities and the acquisition of scientific knowledge in children with learning problems (Alber-Morgan et al., 2015). This would make science education accessible for everyone and it might allow children with learning problems to become proficient scientists. Another reason to start with science programs in kindergarten is that the children with learning-related behaviour problems fall increasingly behind their regular developing peers through development on key topics, such as in reading and mathematics (Morgan et al., 2011). Besides, some kindergartners with learning problems in the present study showed proficiency in experimentation. It shows that kindergartners with learning problems can be educated in scientific reasoning, which allows them to discover and unravel scientific phenomena. In addition, when children produce evidence using scientific methods, they can acquire scientific knowledge, related to the investigated concept (Dunbar and Klahr, 2012).

A limitation of the present study was the sample of kindergartners with learning problems. First, the sample was relatively small. Second, the sample was heterogeneous, with some kindergartners having a clinical diagnosis, while others were just identified as having learning problems. However, this can also be seen as a strength of the present study, as special education schools in Netherlands have such diverse classrooms. Another limitation is the variability on various tasks, such as the verbal working memory task. This could have affected the relationships between the measures. To be able to relate abilities to each other, there should be enough variability in both measures. One final issue is the robustness of learning and possible transfer (Fuchs and Fuchs, 2005). Whether training of experimentation abilities results in transfer of those abilities to other contexts, as in typical developing children (e.g. Chen and Klahr, 1999), was not studied and should be a topic for future research.

To conclude, as a group the kindergartners with learning problems in our study underperform compared to typically developing kindergartners. However, some kindergartners could design multivariable experiments correctly and the performance of both groups of kindergartners did overlap. This indicates that there might be a developmental delay and that scientific activities that include experimentation can just as well be incorporated in early childhood science education of children with learning problems. The individual differences in experimentation abilities of kindergartners with learning problems can be explained by nonverbal reasoning and grammatical abilities, just as in their typically developing peers. Learning via scientific discovery can thus be regarded a suitable instructional method for children with learning problems, especially when they profit from guidance in their reasoning processes and from additional verbal instruction. 


\section{REFERENCES}

Alber-Morgan, S. R., Sawyer, M. R. and Miller, H. L. (2015). Teaching science to young children with special needs. In K.C. Trundle \& M. Saçkes (Eds.), Research in early childhood science education. Springer Science+Business Media. https://doi.org/10.1007/978-94-017-9505-0_14

Anderman, E. M. (1998). The middle school experience: Effects on the math and science achievement of adolescents with LD. Journal of Learning Disabilities, 31, 128-138. https:// doi.org/10.1177/0022219412442154

Andersen, C. and Garcia-Mila, M. (2017). Scientific reasoning during inquiry. In K.S. Taber \& B. Alpan (Eds.), Science Education. New Directions in Mathematics and Science Education (pp. 105-117). https://doi.org/10.1007/97894-6300-749-8_8

Bay, M., Staver, J. R., Bryan, T. and Hale, J. B. (1992). Science instruction for the mildly handicapped: Direct instruction versus discovery teaching. Journal of Research in Science Teaching, 29, 555-570. https://doi.org/10.1002/tea.3660290605

Bleichrodt, N., Drenth, P. J. D., Zaal, J. N. and Resing, W. C. M. (1987). Revisie Amsterdamse kinder intelligentie test. Handleiding. Revision Amsterdam child intelligence test. Manual]. Lisse, the Netherlands: Swets \& Zeitlinger.

Boaler, J. (1993). The role of contexts in the mathematics classroom: do they make mathematics more "real"? For the Learning of Mathematics, 13, 12-17.

Chen, Z. and Klahr, D. (1999). All other things being equal: Acquisition and transfer of the control of variables strategy. Child Development, 70, 1098-1120. https://doi.org/10.1111/1467-8624.00081

Cohen, J. (1988). Statistical power analysis for the behavioral sciences (2nd ed.). Hillsdale, NJ: Erlbaum.

Dawes, L. (2004). Talk and learning in classroom science. International Journal of Science Education, 14, 677-695. https:// doi.org/10.1080/0950069032000097424

Dunbar, K. N. and Klahr, D. (2012). Scientific thinking and reasoning. In K. J. Holyoak \& R. G. Morrison (Eds.), The Oxford handbook of thinking and reasoning. Oxford Handbooks Online. https://doi.org/10.1093/oxfordhb/ 9780199734689.013 .0035

Field, A., Miles, J. and Field, Z. (2012). Discovering statistics using R (3rd ed.). London, UK: Sage Publications.

Fischer, F., Kollar, I., Ufer, S., Sodian, B., Hussmann, H., Pekrun, R., Neuhaus, B., Dorner, B., Pankofer, S., Fischer, M., Strijbos, J., Heene, M. and Eberle, J. (2014). Scientific reasoning and argumentation: advancing an interdisciplinary research agenda in education. Frontline Learning Research, 5, 25-45. https:// doi.org/10.14786/flr.v2i3.96

Freeman, A., Adams Becker, S., Cummins, M., Davis, A. and Hall Giesinger, C. (2017). The NMC/CoSN Horizon Report: 2017 K-12 Edition. Austin, Texas: The New Media Consortium.

Fuchs, D., Compton, D. L., Fuchs, L. S., Bryant, V. J., Hamlett, C. L. and Lambert, W. (2012). First-grade cognitive abilities as long-term predictors of reading comprehension and disability status. Journal of Learning Disabilities, 45, 217-231. https://doi.org/10.1177/0022219412442154

Fuchs, D. and Fuchs, L. S. (2015). Rethinking service delivery for student with significant learning problems: Developing and implementing intensive instruction. Remedial and Special Education, 36, 105-111. https:// doi.org/10.1177/0741932514558337

Inhelder, B. and Piaget, J. (1958). The growth of logical thinking from childhood to adolescence: An essay on the construction of formal operational structures (A. Parsons \& S. Milgram, Trans.). New York, NY: Basic Books. https:/ / doi.org/10.1037/10034-000

Jackendoff, R. (2002). Foundations of language: Brain, meaning, grammar, evolution. New York, NY: Oxford University Press. https:// doi.org/10.1093/acprof:oso/9780198270126.001.0001

Klahr, D. (2000). Exploring Science: The Cognition and Development of Discovery Processes. Cambridge, MA: MIT Press.

Kuhn, D. and Franklin, S. (2006). The second decade: What develops (and how)? In W. Damon \& R. M. Lerner (Eds.), Child and Adolescent Development: An Advanced Course. Hoboken, NJ: John Wiley \& Sons. https://doi.org/10.1002/9780470147658.chpsy0222

Lee, T. H. L. and So, W. W. M. (2015). Inquiry learning in a special education setting: managing the cognitive loads of intellectually disabled students. European Journal of Special Needs Education, 30, 156-172. https:// doi.org/10.1080/08856257.2014.986907

Luria, A. R. and Yudovich, F. I. (1966). Speech and the development of mental processes in the child (J. Simon, Trans. and Ed. and O. Kovasc, Trans.). Guilford, UK: Billing \& sons limited.

Mayer, D., Sodian, B., Koerber, S. and Schwippert, K. (2014). Scientific reasoning in elementary school children: Assessment and relation with cognitive abilities. Learning and Instruction, 29, 43-55. https://doi.org/10.1016/j.learninstruc.2013.07.005

Ministerie van Onderwijs, Cultuur, en Wetenschap. (2014). Toelaatbaarheidsverklaring in het speciaal basisonderwijs [ Permission declaration in special primary education]. Available at: https://www.passendonderwijs.nl/in-enom-de-school/toelaatbaarheidsverklaringen/toelaatbaarheidsverklaring-het-sbo/ 
Ministerie van Onderwijs, Cultuur, en Wetenschap. (2016). Factsheet speciaal basisonderwijs en special onderwijs [Factsheet special primary education and special education]. Available at: https://www.passendonderwijs.nl/wpcontent/uploads/2016/10/Fatsheet-sbo-en-so.pdf

Morgan, P. L., Farkas, G. and Wu, Q. (2011). Kindergarten children's growth trajectories in reading and mathematics: Who falls increasingly behind? Journal of Learning Disabilities, 44, $472-488$. https://doi.org/10.1177/0022219411414010

Parmar, R. S., Deluca, C. B. and Janczak, T. M. (1994). Investigations into the relationship between science and language abilities of students with mild disabilities. Remedial and Special Education, 15, 117-126.

Ponitz, C. C., McClelland, M. M., Matthews, J. S. and Morrison, F. J. (2009). A structured observation of behavioral self-regulation and its contribution to kindergarten outcomes. Developmental Psychology, 45, 605-619. https://doi.org/10.1037/a0015365

Resing, W. C. M., Bleichrodt, N., Drenth, P. J. D. and Zaal J. N. (2012). Revisie Amsterdamse kinder intelligentie test 2. Handleiding. [Revision Amsterdam child intelligence test 2. Manual]. Amsterdam, the Netherlands: Pearson Assessment and Information.

Siegel, L. S. and Ryan, E. B. (1989). The development of working memory in normally achieving and subtypes of learning disabled children. Child Development, 60, 973-980. https:/ / doi.org/10.2307/1131037

Siegler, R. S. and Chen, Z. (1998). Developmental differences in rule learning: A microgenetic analysis. Cognitive Psychology, 36, 273-310. https:/ / doi.org/10.1006/cogp.1998.0686

Siler, S., Klahr, D., Magaro, C., Willows, K., Mowery, D. (2010). Predictors of transfer of experimental design skills in elementary and middle school children. In V. Aleven, J. Kay and Mostow, J. (Eds.), Intelligent Tutoring Systems 6095. Berlin \& Heidelberg, Germany: Springer-Verlag. https://doi.org/10.1007/978-3-642-13437-1_20

Snow, C. E. (2010). Academic language and the challenge of reading. Science, 328, $450-452$. https://doi.org/10.1126/science.1182597

Van der Graaf, J., Segers, E. and Verhoeven, L. (2015). Scientific reasoning abilities in kindergarten: Dynamic assessment of the control of variables strategy. Instructional Science, 43, 381-400. https://doi.org/10.1007/s11251-015-9344-y

Van der Graaf, J., Segers, E. and Verhoeven, L. (2016). Scientific reasoning in kindergarten: Cognitive factors in experimentation and evidence evaluation. Learning and Individual Differences, 49, $190-200$. https://doi.org/10.1016/j.lindif.2016.06.006

Van der Steen, S., Steenbeek, H., Wielinksi, J. and Van Geert, P. (2012). A comparison between young students with and without special needs on their understanding of scientific concepts. Education Research International, 2012, 1-12. https://doi.org/10.1155/2012/260403

Verhoeven, L., Keuning, J., Horsels, L. and Van Boxtel, H. (2013). Testinstrumentarium taalontwikekelingsstoornissen: Indicatiestelling taal- en spraakproblematiek. TTest instrumentation language development disorders: Assessment language and speech problems]. Amsterdam, the Netherlands: Boom Test Uitgevers.

Wagensveld, B., Segers, E., Kleemans, T. and Verhoeven, L. (2015). Child predictors of learning to control variables via instruction or self-discovery. Instructional Science, 43, 365-379. https://doi.org/10.1007/s11251014-9334-5

Wanless, S. B., McClelland, M. M., Acock, A. C., Ponitz, C. C., Son, S., Lan, X., Morrison, F. J., Chen, J., Chen, F., Lee, K., Sung, M. and Li, S. (2011). Measuring behavioral regulation in four societies. Psychological Assessment, 23, 364-378. https://doi.org/10.1037/a0021768

Werker, J. F., Fennell, C. T., Corcoran, K. M. and Stager, C. L. (2002). Infants' ability to learn phonetically similar words: Effects of age and vocabulary size. Infancy, 3, 1-30. https://doi.org/10.1207/S15327078IN0301_1

Wilkening, F. and Huber, S. (2004). Children's intuitive physics. In U. Goswami (Ed.), The Blackwell handbook of childhood cognitive development. Blackwell Reference Online. https://doi.org/10.1111/b.9780631218418.2004. 00019.x 